\title{
O processo saúde-doença e os cuidados com a saúde na perspectiva dos educadores infantis
}

\author{
The health-illness process and health care \\ from the perspective of child care providers
}

\footnotetext{
1 Universidade Santo Amaro. Rua Diogo Rodrigues Marques 56, Santo Amaro, SP 04677-040, Brasil. damarisgm@uol.com.br
}

\begin{abstract}
This article presents a case study of a public daycare center for low-income children in the city of São Paulo. Anthropological analysis focused on the organization and use of space, daily care, and rules of hygiene, reflecting values used by adults to organize social reality.

Key words Child Rearing; Continuing Education; Health Education; Health-Disease Process
\end{abstract}

Resumo Este artigo apresenta um estudo de caso realizado em creche pública que é administrada por uma entidade filantrópica e atende a população de baixa renda da periferia da cidade de São Paulo. O uso e a organização do espaço, a rotina de cuidados e as regras de higiene adotadas, quando analisadas à luz da antropologia, revelam os valores pelos quais os adultos ordenam o seu mundo social.

Palavras-chave Educação Infantil; Educação Contínua; Educação em Saúde; Processo SaúdeDoença 


\section{Introdução}

A Política Nacional de Educação Infantil aponta a necessidade de formação regular dos educadores infantis, considerando que $18,9 \%$ dos professores de pré-escola são leigos e, em algumas regiões do país, superam um terço do corpo docente. Nas creches, o quadro é ainda mais grave, por terem sido inseridas apenas recentemente no âmbito da educação (MEC, 1994, 1996).

A formação de educadores infantis, além de prepará-los para o desenvolvimento do projeto pedagógico, demanda a inclusão de conteúdos relativos à promoção à saúde, tendo como finalidade aprimorar a qualidade dos serviços prestados às crianças, reduzindo o risco de adoecimento, o qual, segundo vários autores, é maior nas crianças que freqüentam creches em relação àquelas que são cuidadas no contexto familiar (Barros, 1996; Solomon \& Cordell, 1996).

O objetivo deste artigo é apresentar os resultados de uma pesquisa sobre as concepções dos educadores que embasam os cuidados cotidianos que prestam às crianças. Em sua íntegra, constitui dissertação de mestrado em Enfermagem apresentada à Universidade Federal de São Paulo (Maranhão, 1998).

\section{Metodologia}

Realizou-se uma pesquisa qualitativa - através de estudo de caso - em creche pública filantrópica, na zona sul periférica da cidade de São Paulo. O estudo focou o atendimento de crianças de 0 a 2 anos. Foram utilizadas técnicas de observação; análise de documentos e entrevistas. Estas foram efetuadas com dez educadores, diretor, pedagogo e auxiliar de enfermagem da creche. A observação foi feita entre os meses de agosto a dezembro de 1996, tendo sido registrada em diário de campo. As entrevistas seguiram roteiro semi-estruturado elaborado com base nos pressupostos e hipóteses, construídos tanto na definição do objeto de investigação, quanto nas observações. O roteiro apenas serviu de guia para o pesquisador, não cerceando a fala dos entrevistados. Os dados colhidos foram de duas naturezas:

a) O cotidiano da criança na creche e os cuidados que recebe; as concepções que norteiam os cuidados e atividades educativas com as crianças; os problemas de saúde e os procedimentos para resolvê-los.

b) Os dados que se referem ao entrevistado, ou seja, suas vivências, percepções, valores e opiniões a respeito do cuidar.
A análise foi feita após a contextualização das entrevistas com base na descrição da creche, incluindo a organização do trabalho e a rotina de cuidados, compondo um quadro com os registros do diário de campo.

A creche atendia 180 crianças de segunda a sexta-feira, das 7 às 17 horas, cujas famílias tinham renda de até três salários mínimos. A equipe era composta por diretor, pedagogo, auxiliar de enfermagem, 16 educadores, quatro cozinheiras, um zelador e três auxiliares de limpeza. Embora a exigência quanto à formação para contratação dos educadores leigos fosse de primeiro grau completo, oito estavam concluindo o segundo grau e quatro tinham formação em magistério. Todas as educadoras eram mulheres, com idades que variavam entre 20 e 40 anos de idade.

A opção por creche pública filantrópica foi feita em razão de ter-se tomado em conta que o maior número de creches é deste tipo, bem como pela tendência do atual governo de repasse dos serviços públicos para cooperativas, entidades e iniciativa privada. Foram consideradas as condições básicas de operacionalização prédio conforme as normas técnicas e equipe de acordo com recomendações do convênio municipal. O berçário - composto por duas salas, lactário, sala de banho e troca, copa para refeições e solário - foi planejado para atender 30 crianças de 0 a 18 meses, mas havia 39 crianças matriculadas, seguindo recomendações do convênio que prevê otimização das vagas em razão da variação na freqüência diária.

\section{Resultados e discussão}

A doença como resultado de determinantes exteriores - o estigma da doença reforçando preconceitos em relação aos usuários da creche

O conhecimento a respeito do processo saúdedoença está associado às concepções que explicam o mundo, os costumes, os valores e as crenças da sociedade em que é gerado, refletindo o pensamento dominante em dado momento histórico. Esta concepção hegemônica pode coexistir com outras formas de explicar e lidar com o processo saúde-doença em cada contexto (Minayo, 1996).

Os educadores desta creche atribuem o adoecimento das crianças a determinantes exteriores à instituição: variações climáticas, condições de vida e, principalmente, aos cuidados prestados pelos familiares. A atribuição causal da doença com ênfase nos fatores exter- 
nos ou nos cuidados prestados pelas famílias pode ser analisada de acordo com o que Barros (1996) e Piotto et al. (1996) referem como resistência das equipes de creches em avaliarem o seu próprio trabalho e o serviço prestado aos usuários. Esta forma simplista de analisar os problemas de saúde das crianças impede que se aprofunde na busca de indicadores de avaliação da qualidade dos cuidados nas creches, assim como reforça preconceitos em relação aos usuários do serviço, dificultando a construção de uma parceria entre pais e educadores em benefício da criança.

“... que nem estas crianças que têm problemas de saúde, eu acho que isso precisa mais de um acompanhamento psicológico e não assim... falta de carinho dos pais, falta de amor dos pais, por parte dos pais" (auxiliar de enfermagem).

Ao perceberem que as crianças adoecem mais quando entram na creche, atribuem tal fato ao ambiente que as crianças estranham, mas não associam com os cuidados no processo de adaptação que poderia contribuir para reduzir estes agravos.

"No começo eu achava que as crianças, que elas tinham... eu não sei se um problema de saúde, mas elas (as outras educadoras) falavam que criança de creche era daquele jeito mesmo, né, $e$ eu pensava que isso era a alimentação... que eles não estavam acostumados..." (educadora).

As doenças infecciosas e parasitoses encontram no ambiente coletivo condições para serem disseminadas, mas são associadas diretamente à falta de higiene e à pobreza da família, em contraposição às mães que afirmam que os filhos adoecem mais depois que estão na creche.

"Nossa, era horrível demais, diarréia direto, eu não sei se era contagiosa... às vezes quando você via, 'tavam' todas as crianças com diarréia. Catapora, todas as crianças do berçário começaram a pegar catapora, uma por uma, né, assim, uma ia embora, a outra já voltava... e pneumonia, eu achei que muitas crianças pegaram pneumonia. Sempre teve casos, sempre, crianças sempre gripadas, mas tinha criança que eu achava que nunca teve gripe" (educadora).

Reiterando o que apontamos, admitir que a doença tenha sido transmitida na creche é mais difícil que imputar a responsabilidade à família da criança. O estigma da doença reforça os preconceitos em relação aos familiares.

\section{Cuidados com a promoção da saúde na creche - a quem compete?}

A avaliação da saúde feita pelos educadores é baseada em suas percepções derivadas do diaa-dia com as crianças. Sendo responsável pelo cuidado e educação de um grupo infantil, eles identificam empiricamente os primeiros sinais de mal-estar e os problemas de saúde mais freqüentes.

"Ah, no caso de saúde, é tá sempre olhando, sabe é... tipo assim, a gente tá sempre prestando atenção, vendo se a criança está bem... pois como a gente já conhece a criança, a gente sabe assim... quando ela está meio quietinha assim, se... você já percebe se ela está legal ou não, porque... se você vê todo dia ela, o jeito dela, de repente ela tá meio caidinha assim... você já pensa... será que ela está com febre, será que está assim, aí já vai ver se ela está com febre, se tiver febre, já pede pra T. (auxiliar de enfermagem), indicar alguma coisa, ou até dá um banho, essas coisas" (educadora).

Percebem que a creche pode contribuir para a promoção da saúde, mas atribuem tais ações aos profissionais e serviços de saúde, não relacionando com as condições e práticas de cuidado cotidiano que são da competência dos educadores.

"Assim que a criança tava com diarréia, a gente conversava com auxiliar de enfermagem, ela dava um encaminhamento para a mãe, que levava a criança no médico, essas coisas assim...e acabou...não sei porque diminuiu...mas sei que melhorou bastante" (educadora).

Nesta perspectiva, os cuidados com a saúde são compreendidos como ações especiais que visam o controle e o tratamento das doenças restritos à dimensão biológica; por exemplo, aos nutrientes que compõe o cardápio e não à forma como as refeições são organizadas e oferecidas às crianças. $\mathrm{O}$ modo como o cuidado é oferecido, o cuidado em si, em sua dimensão afetiva e cultural, raramente é associado com a qualidade de vida no interior da instituição que repercute no bem estar e saúde infantil.

"No caso da diarréia, se é uma criança... mas às vezes são duas, três, quatro, tudo ao mesmo tempo... o que é isto? De repente descobriram que era a caixa, principalmente do berçário, aquela torneira não passa água filtrada. Descobrimos quando houve um problema na caixa e quando ligaram saiu aquele caldo todo enferrujado. Se tivesse passado pelo filtro, não saia daquele jeito. Olha aí onde estavam os problemas das infecções intestinais! Depois que nós descobrimos isto, melhorou, acho que era a água mesmo. Acho não, era a água!" (educadora).

Os agravos coletivos são atribuídos às causas exteriores dos procedimentos de cuidado com a criança, como a qualidade da água. Não se associa com a falta de higiene adequada das mãos dos educadores que tanto servem as refeições e oferecem mamadeiras, como trocam 
e pré-lavam fraldas, o que, quando se investiga, é o principal motivo que favorece a alta freqüência de diarréias e hepatite infecciosas nas creches (MS, 1987; Barros, 1996; Solomon \& Cordell, 1996).

Os cuidados com a saúde e as regras de higiene: re-interpretando as informações

Embora os cuidados com a saúde sejam, muitas vezes, compreendidos como cuidados com o corpo, há uma ordem de significações culturais mais abrangentes que recorta o olhar sobre o corpo e sua relação com a higiene e com a saúde, correspondendo às contradições de determinada visão de mundo e de uma organização social (Minayo, 1996).

As informações para os educadores acerca dos cuidados com a saúde são adquiridas em breves treinamentos iniciais, sendo que na prática aprendem de forma artesanal, observando outros educadores trabalhando. Estas informações são assimiladas de forma parcial, ou são reinterpretadas segundo os conhecimentos prévios dos educadores e o recorte que fazem sobre o corpo e sua relação com a higiene e saúde.

"Nós fomos visitar uma creche, naquele mês de treinamento, e lá eu vi um jeito que a educadora dava banho, após esterilizar a banheira com cloro. Aqui a gente não tá usando. No início, a gente usava muito cloro, cada banho, passar cloro na banheira... eu uso a esponja sabe, a cada banho eu uso a esponja... no meu berçário não tem esses problemas de pele. Eu não sei, porque também, se não lavar a banheira fica aquele sebinho, ali, grudado na banheira, porque eles (as crianças) têm uma gordurinha, né, o suor deles, né, fica tudo ali" (educadora).

Os cuidados com a higiene são diretamente associados à promoção da saúde, podendo ou não ser valorizados segundo as concepções dos educadores e a forma como o trabalho com a criança está organizado. Nem sempre os educadores cumprem as normas prescritas, tanto por não estarem convencidos da importância das mesmas, quanto pelo que consideram sujo e limpo. A atribuição do significado ao que é sujo - portanto, impuro ou maléfico - ou ao que é limpo, ou puro - portanto, benéfico - é socialmente construído, revelando muito mais do que a microbiologia fundamenta as regras de assepsia (Douglas, 1966).

"A educadora me perguntou: Você acha certo que uma mãe chegue e dê de mamar pra outra criança? Eu falei - não, não é certo, e nem pode, como que isso aconteceu? Daí ela me explicou, que a criança tava chorando muito... quando esta criança entrou aqui ela mamava no peito, eu não me lembro direito, e daí a educadora $X$ deu o peito pra essa criança (uma educadora que amamentava o filho) eu falei, não pode, primeiro porque ela não tem autorização da mãe da criança que possa dar ou não, e segundo por causa da AIDS e outras doenças. Daí ela falou assim: mas a educadora X é sã, e eu falei como você pode provar? Daí ela falou: Ah, você está sendo muito radical... Outra educadora achou normal, porque ela é do interior e lá as pessoas davam de mamar pra outras crianças..." (auxiliar de enfermagem).

A auxiliar de enfermagem da creche procura orientar as educadoras e fazer cumprir as normas de higiene. Mas a qualidade dos cuidados com a saúde não passa simplesmente pela normatização de regras, e sim pela interpretação que o educador faz destas regras e pelas condições reais que encontra para operacionalizá-las. No momento em que a situação cotidiana exige uma tomada de decisão, a escolha sofre influências do senso comum e das práticas tradicionais que nossa cultura tem em relação ao cuidado com as crianças.

"Uma educadora informou que a sua parceira de trabalho havia usado a mesma mamadeira para dar suco pra mais de uma criança. Daí eu fui conversar com a educadora e ela me explicou que tava muito corrido, e ela estava sozinha, as crianças todas chorando, e ela pegou e... encheu a mamadeira pra um, a criança tomou só um pouquinho do suco e deixou, ela deu pro outro... Perguntei se ela não sabia que isto era errado. Ela falou: Sei, fiz consciente, e tô falando a verdade. Ó, eu sei que é errado, mas também sei que não ia prejudicar... eu acho que as crianças do berçário são todas sadias" (auxiliar de enfermagem).

Por um lado, é possível que a educadora tenha "transgredido" a norma não apenas pelas condições de trabalho, mas por ter re-interpretado os procedimentos prescritos com base no discurso ambíguo daqueles que defendem que na creche não há necessidade de cuidados com a saúde, pois "afinal todas as crianças são sadias". Por outro lado, na concepção da colega, ela infringiu a ordem, cometeu um erro pelo qual foi punida com a transferência do setor. No entanto, se compararmos com a outra regra que também foi transgredida, ou seja, o fato de uma educadora ter amamentado um bebê do berçário, tanto do ponto de vista do risco à saúde, quanto do ponto de vista ético, a reação daqueles que julgaram o acontecido permitiu observar que algumas normas de higiene podem parecer mais importantes que outras, dependendo de quem as interpreta e do contexto sociocultural. 


\section{Criança saudável é criança "limpa"?}

O cuidado com as crianças na esfera da família ou da creche é perpassado pelos sentidos que os atores sociais atribuem às práticas de cuidado e, por sua vez, expressam os sentidos que dão para a saúde e para a higiene.

"Como se sabe, a sujeira é, essencialmente desordem. Não há sujeira absoluta: ela existe aos olhos de quem a vê. Se evitarmos a sujeira não é por covardia, medo, nem receio ou temor divino. Tampouco nossas idéias sobre doença explicam a gama de nosso comportamento no limpar e no evitar a sujeira. A sujeira ofende a ordem. Eliminá-la não é um movimento negativo, mas um esforço positivo para organizar o ambiente" (Douglas, 1966:12).

Em nossa sociedade, a própria noção de criança "saudável" é associada à criança "limpa". Criança saudável é criança "bem cuidada" e vice versa. E criança "bem cuidada" é criança "limpa". O inverso também é verdadeiro, pois deixar que as crianças permaneçam no chão, à vontade, pode ser interpretado como sinônimo de criança mal cuidada, de descuido.

"Ah, bem cuidada... eu acho... a gente vê se a criança está bem de saúde, se está limpinha... a roupa limpinha, a unha bem cortadinha... sem piolho, tá sempre de olho, vê se ela está bem de saúde, levar ao médico assim, acho que são esses os cuidados" (educadora).

Do ponto de vista da promoção do desenvolvimento, colocar os bebês no chão do berçário é prática que proporciona a oportunidade para que eles se movimentem, explorem o ambiente, interajam com outras crianças, ainda que possa entrar em contradição com as concepções a respeito de cuidado e sobre cuidar da saúde, mesmo entre aqueles que têm formação universitária.

"Então isso me preocupa, vai pôr a criança no chão? Além de que tem aquela questão, parece que está largada, não sei o que, não é nem isto. Eu fui criada no chão, minha mãe colocava a gente desde cedo no chão, mas a casa era de madeira, é alta do chão, então não era fria" (diretora da creche).

Associar o colocar no chão com "descuido" pode resultar em restringir o tempo e a idade em que as crianças são deixadas livres fora do berço para explorar o ambiente, o que traz a possibilidade de atrasar seu desenvolvimento motor. A equipe considera a creche "fria", embora o prédio seja de construção sólida e não haja presença de sinais de umidade, além de o piso ser revestido com material isolante. $\mathrm{O}$ frio é associado com a causa principal das infecções respiratórias que são freqüentes entre as crianças; assim, "estar no chão frio" seria descuido. Com base nesta concepção, os membros da equipe protegem as crianças menores nos berços (embora possam protegê-los com agasalhos) e forram o centro da sala com um tapete felpudo, ainda que este não impeça o contato com o chão, pois as crianças, ao se locomoverem, não respeitam limites. Paradoxalmente, o tapete pode aumentar o risco de infecções respiratórias por acumular poeira e ácaros. Em nossa análise, o uso do tapete teria a função de aconchego, portanto de "aquecer" o ambiente tanto no sentido literal como metaforicamente, já que a maioria dos educadores referem uma ambigüidade em relação ao seu trabalho, pois acreditam que os bebês deveriam estar sendo cuidados por suas mães e, não o sendo, são rotulados como "carentes" de afeto e a creche "fria".

Estes fatos nos levam a cogitar que os cuidados muitas vezes são planejados com base na necessidade dos adultos, não se considerando as reais necessidades infantis. Ou seja, a escolha de determinado cuidado em detrimento de outro pode ter o sentido de aplacar a insegurança dos adultos, tranqüilizando a equipe e expressando suas intenções de cuidar bem.

Neste estudo, procuramos refletir sobre o caráter relativo das concepções dos educadores e, a partir daí, pôr em discussão, abrir caminhos para que a organização do cuidar/educar nas creches possa contemplar a promoção do crescimento e desenvolvimento saudável.

\section{Considerações finais}

Os resultados desta pesquisa reafirmam a necessidade de considerarmos, em qualquer projeto de formação e de educação para a saúde, as concepções prévias da população alvo. No caso específico dos educadores infantis, aponta a necessidade de inclusão dos conhecimentos sobre o processo saúde-doença nos currículos de formação inicial ou continuada, sempre tomando em conta a dimensão histórica e cultural. Este estudo de caso, embora restrito a uma creche, revela concepções que podem estar norteando, neste momento histórico, as práticas de cuidados com crianças em creches com as mesmas características, o que tenho confirmado em minha atuação em projetos de formação em outras creches da cidade de São Paulo e em outras cidades e Estados. 


\section{Agradecimentos}

A autora agradece às doutoras Cynthia Andersen Sarti e Conceição Vieira da Silva, respectivamente, orientadora e co-orientadora de sua Dissertação de Mestrado, intitulada "O Cuidado como Elo entre a Saúde e a Educação: Estudo de Caso no Berçário de uma Creche", pela Universidade Federal de São Paulo.

\section{Referências}

BARROS, A. J. D., 1996. Health Risks among Child Day Care Centre Attendees: The Role of Day Care Centre Characteristics in Common Childhood Illnesses. Ph.D. Thesis, London: London School of Hygiene and Tropical Medicine, University of London.

DOUGLAS, M., 1966. Pureza e Perigo. São Paulo: Perspectiva.

MARANHÃO, D. G., 1998. O Cuidado como elo Entre a Saúde e a Educação: Um Estudo de Caso no Berçário de uma Creche. Dissertação de Mestrado, São Paulo: Universidade Federal de São Paulo.

MEC (Ministério da Educação e do Desporto), 1994. Por uma Política de Formação do Profissional de Educação Infantil. Brasília: MEC.

MEC (Ministério da Educação e do Desporto), 1996. LDB. Aspectos Relevantes para a Educação Infantil (Lei 9.394 de 20 de dezembro de 1996). Brasília: Ministério da Educação e do Desporto.

MINAYO, M. C. S., 1996. O Desafio do Conhecimento: Pesquisa Qualitativa em Saúde. 4a Ed. São Paulo: Editora Hucitec.

MS (Ministério da Saúde), 1987. Manual de Controle de Infecção Hospitalar. Brasília: Centro de Documentação, Secretaria Nacional de Organização e Desenvolvimento de Serviços de Saúde, Ministério da Saúde.

PIOTTO, D. C.; ROSSETTI-FERREIRA, M. C.; CHAGURI, A. C.; MELLO, A. M.; SILVA, A. P.; ELTINK, C.; YAZZLE, C. H.; CARNIEL, I. C.; DE SORDI, G.; BALDIN, L. S. A.; FREDERIK, M. I. B.; MORAIS, R. \& BESANI, V., 1996. Promoção da Qualidade e Avaliação na Educação Infantil: Contribuições da Experiência com um Instrumento Australiano para a Discussão Brasileira. São Paulo: Faculdade de Filosofia, Ciências e Letras de Ribeirão Preto, Universidade de São Paulo.

SOLOMON, S. L. \& CORDELL, R. L., 1996. Infection acquired in day care centers. In: Hospital Epidemiology and Infections Control (C. G. Mayhall, ed.), pp. 564-583, Galveston: Williams \& Wilkins. 